\title{
Prevalence of skin tears in hospitalized adults and older adults
}

\author{
Prevalência de lesões por fricção em adultos e idosos hospitalizados \\ Prevalencia de lesiones por fricción en adultos y adultos mayores hospitalizados
}

How to cite this article:

Souza LM, Teixeira GS, Silva DM, Ruiz LS, Coppola IS, Meirelles LCS. Prevalence of skin tears in hospitalized adults and older adults. Rev Esc Enferm USP. 2021;55:e03683. doi: https://doi.org/10.1590/S1980-220X2019025103683

\author{
Luccas Melo de Souza ${ }^{1}$ \\ Gabriela da Silva Teixeira² \\ Débora Monteiro da Silva ${ }^{2}$ \\ Letícia da Silva Ruiz ${ }^{2}$ \\ Isabella dos Santos Coppola ${ }^{2}$ \\ Lisiani Celina da Silva Meirelles ${ }^{3}$ \\ 1 Universidade Federal de Ciências da \\ Saúde de Porto Alegre, Departamento de \\ Enfermagem, Porto Alegre, RS, Brazil \\ 2 Universidade Luterana do Brasil, \\ Campus Gravataí, Gravataí, RS, Brazil. \\ 3 Fundação Universitária de Cardiologia, \\ Instituto de Cardiologia do Rio Grande \\ do Sul, Porto Alegre, RS, Brazil.
}

\begin{abstract}
Objective: To identify the prevalence, related factors and to classify Skin Tears in hospitalized adults and older adults. Method: Prevalence study with adults and older adults in inpatient and intensive care units of a hospital in the South Region of Brazil. The STAR Skin Tear Classification System was used to analyze the lesions. Data were collected by physical examination and consultation of medical records. The Poisson Regression Prevalence Ratio with robust variance was calculated. Results: The participants were 148 patients. There were 29 Skin Tears (mean $1.6 \pm 0.7$ ) in 18 individuals (prevalence of $12.2 \%$ ). The variables age, friable skin, enteral feeding catheter, degree of dependence, use of antihypertensives, micronutrients, diuretics, antidepressants, and antifungals were associated with lesions in the bivariate analysis. In the final multivariate model, antihypertensives PR 2.42 (95\%CI 1.01-5.77), antidepressants PR 2.72 (95\%CI 1.1-6.33) and micronutrients PR 4.93 (95\%CI 1.64-14.80) maintained a relationship. Conclusion: The prevalence of injuries was $12.2 \%$, showing they are present in the health care setting, especially in nursing care. Care protocols need to be developed for the prevention, identification and early treatment of ST.
\end{abstract}

DESCRIPTORS

Wounds and Injuries; Friction; Skin; Inpatients; Nursing Care. 


\section{INTRODUCTION}

Skin tears (ST) are traumatic wounds caused by friction, contusion and/or shearing of the skin, affecting mainly the extremities of the limbs. They occur mostly in extremes of age (older adults and neonates) and in critically ill and/or care-dependent individuals, and are characterized by the separation of the epidermis from the dermis or separation between the epidermis and dermis from the hypodermis ${ }^{(1-2)}$.

ST have a definition and have been studied since the mid1990s, however, there is still little epidemiological data on it, especially in Latin American countries, where research on the topic is scarce. Some researchers suggest that, although they may be more prevalent than Pressure Injuries, ST go unnoticed, perhaps because they are shallow traumatic wounds and are mistakenly considered inherent to the aging process ${ }^{(1-4)}$.

The impact of ST is associated with increased pain, higher costs and hospitalization rates, development of chronic wounds, decreased mobility and reduced quality of life ${ }^{(5-6)}$. However, simple measures such as the identification of patients at risk and the implementation of prevention protocols seem to reduce its severity or even prevent $S T^{(3,7)}$.

The occurrence of ST is associated with intrinsic and extrinsic risk factors, many of which still need to be better defined. Known factors include extremes of age, female gender, Caucasian race, nutritional alterations, use of medications (such as anti-inflammatories, corticosteroids, immunosuppressants and anticoagulants), smoking, comorbidities, dependence for activities and sensory alteration, among others ${ }^{(1,6)}$. International studies indicate a prevalence between 3.9 and $22 \%(2,8)$.

The identification of individuals with these risk factors and the implementation of preventive measures have been effective in preventing ST, reducing its rates and minimizing its severity ${ }^{(9)}$. Thus, aiming to provide theoretical data on ST in the Brazilian context and considering the scarcity of national studies, the following research questions arose: what is the prevalence of ST in adult patients admitted to a Brazilian hospital? What characteristics are related to the occurrence of ST?

Based on these guiding questions, this study aims to identify the prevalence of Skin Tears in adult and older adults admitted to a hospital in the Metropolitan Region of Porto Alegre, Rio Grande do Sul state. The specific objectives are to classify the type of ST and to identify the factors associated with its presence.

The study is justified by the economic, clinical and social impact of ST, the scarcity of national studies (especially in the context of public health care in Brazil) and the trend to have a higher number of cases of ST due to the population aging process ${ }^{(4)}$.

\section{METHOD}

\section{StUdV DESIGN}

This is a prevalence study.

\section{SCENARIO}

The study was developed in three Adult Inpatient Units (clinical and surgical) and an Intensive Care Unit (ICU) of a hospital in the Metropolitan Region of Porto Alegre/RS. It was a general and medium-size hospital, that served public health through the Unified Health System (SUS - Sistema Unico de Saúde), private health insurance and private patients.

\section{Population}

The study population comprised all patients admitted to the Adult Inpatient Units or to the hospital's ICU during the data collection period.

The inclusion criteria were: being at least 18 years old; being hospitalized in the ICU beds or in the Adult Inpatient Unit on the days of data collection. Exclusion criteria were: being hospitalized in one of the psychiatric beds (drug users or suicide attempts), maternity beds and/or in rooms with anti-contagion measures for diseases transmitted through contact, droplets or air particles, due to the restriction of entry into these rooms, as requested by hospital infection control.

The three Adult Inpatient Units have 129 beds, of which many are destined for maternity, with no exact pre-defined number for distribution. The ICU has 10 fixed beds. Thus, the maximum capacity for hospitalization is 139 beds in the Adult Inpatient Units and the ICU. A sample of 148 subjects was calculated, considering a $22 \%$ prevalence of $\mathrm{ST}^{(8)}$ and a sampling error of less than 5\%. Two data collections were carried out to reach a total of 148 patients who agreed to participate in the study, as there were 25 refusals, 48 exclusions by criteria and 57 vacant beds.

\section{Data collection}

The data was collected in October 17 and November 17, 2017.

A pilot test with five patients was carried out before official data collection, aiming to adapt the instrument and systematize the process. The data were collected by a nurse with a doctoral degree, who was the responsible researcher, and by four nursing students who underwent theoretical and practical training on the evaluation of ST. Content related to its definition, identification, classification and related factors were addressed, as well as the standard application of the instrument.

The instrument contained socio-demographic (gender, age, skin color) and clinical data. The clinical variables investigated were medical diagnosis, Body Mass Index (BMI), diet received via gastric/enteral catheter or oral diet, oxygen received via oxygen support device or room air ventilation, characteristic of the skin, dependence for Basic Activities of Daily Living (BADL) and use of vascular catheters, tape/ adhesive device on the skin, mechanical restraints, medications or micronutrients. Vitamins and glucose were considered micronutrients.

The physical examination performed on patients consisted of visual inspection (performed only once) to search for lesions, assess the type of skin and categorize the ST, when detected. Friable skin (assessed subjectively) refers to a fragile brittle skin with reduced turgor and similar to a "sheet of paper". 
The Brazilian version of the STAR Skin Tear Classification System was used to evaluate the $\mathrm{ST}^{(10)}$. The adapted version had a moderate and statistically significant level of agreement when applied in clinical practice and proposes five categories ( $1 \mathrm{a} ; 1 \mathrm{~b} ; 2 \mathrm{a} ; 2 \mathrm{~b}$ e 3$)$ :

Level 1a: a skin tear where the edges can be realigned to the normal anatomical position (without undue stretching) and the skin or flap color is not pale, dusky or darkened;

Level 1b: a skin tear where the edges can be realigned to the normal anatomical position (without undue stretching) and the skin or flap color is pale, dusky or darkened;

Level 2a: a skin tear where the edges cannot be realigned to the normal anatomical position (without undue stretching) and the skin or flap color is not pale, dusky or darkened;

Level 2b: a skin tear where the edges cannot be realigned to the normal anatomical position (without undue stretching) and the skin or flap color is pale, dusky or darkened;

Level 3: a skin tear where the skin flap is completely absent.

The data regarding the classification of the ST, when prevalent, were evaluated by two researchers, one of whom was the researcher with the highest academic degree (doctorate). The modified Katz Index was used to assess BADL at the time of physical examination. The index indicates when the patient is independent (the sum of the score is 06) or dependent (score between 01 and 05). A score of zero indicates total dependence ${ }^{(11)}$.

Medical diagnoses were collected from medical records and grouped according to the International Classification of Diseases (ICD-10) ${ }^{(12)}$. For the BMI classification, the World Health Organization definition was used ${ }^{(13)}$ : underweight (below $18.5 \mathrm{~kg} / \mathrm{m}^{2}$ ), normal weight (18.5 to $24.9 \mathrm{~kg} / \mathrm{m}^{2}$ ), overweight (25 to $29.9 \mathrm{~kg} / \mathrm{m}^{2}$ ), obesity (30 to $39.9 \mathrm{~kg} / \mathrm{m}^{2}$ ) and severe obesity (above $40 \mathrm{~kg} / \mathrm{m}^{2}$ ). Weight and height information was collected according to the patient's report or, as a second option, from the medical record, according to the institution's nutrition service record. This information was not obtained for all patients in the sample.

\section{DATA ANALYSIS AND TREATMENT}

Data analysis was conducted in the Statistical Package for Social Sciences for Windows version 25, using descriptive statistics (frequency, percentage, mean and standard deviation), inferential statistics (Prevalence Ratio with 95\% confidence interval) and Poisson Regression analysis with robust variance (bi and multivariate). Two multivariate regression models were applied: the first included all variables that showed a significant relationship $(\mathrm{p}<0.05)$ with the occurrence of ST in the bivariate analysis; the second model excluded the age variable. The variable friable skin was not included in the multivariate model, as it is known to be related to ST. Values with two-tailed $\mathrm{p}<0.05$ were considered statistically significant.

\section{ETHICAL ASPECTS}

The study was approved by the Research Ethics Committee of the Universidade Luterana do Brasil, protocol
2.306.692/2017, in accordance with Resolution no. 466/2012, of the National Health Council, on research with human beings. The risks to participation are minimal as there were no interventions, only interviews and physical exams, which were considered a discomfort due to the duration and manipulation of the participants. All participants signed an Informed Consent Form (ICF).

\section{RESULTS}

Among the 148 subjects, there was a slight predominance of females $(n=76 ; 51.3 \%)$, the mean age was $60.1 \pm 19$ years, most had no partner $(n=76 ; 51.3 \%)$ and there was a predominance of white participants $(n=120 ; 81.0 \%)$, followed by brown (pardos) $(n=18 ; 12.2 \%)$ and blacks $(n=10 ; 6.8 \%)$.

The prevalence of ST was $12.2 \%(n=18)$. No ST was identified in patients admitted to the ICU $(p=0.128)$. As for the number of ST, ten people (55.6\%) had one injury, five had two injuries and three had three injuries, representing a mean of $1.6 \pm 0.7$ injuries per patient, out of a total of 29 ST. The location and classification of the ST are described in Table 1.

Table 1 - Characteristics related to Skin Tears - Metropolitan Region of Porto Alegre, RS, Brazil, 2017.

\begin{tabular}{lc}
\hline Variables & $\mathbf{n = 2 9}$ \\
\hline Location and Classification of the Skin Tears & $\mathbf{n}(\%)$ \\
\hline Head 1a & $1(3.4)$ \\
Left Arm 1a & $2(7.0)$ \\
Left Arm 3 & $1(3.4)$ \\
Right Forearm 1a & $6(20.7)$ \\
Right Forearm 1b & $2(7.0)$ \\
Right Forearm 3 & $1(3.4)$ \\
Left Forearm 1a & $6(20.7)$ \\
Left Forearm 3 & $2(7.0)$ \\
Right Hand 1a & $1(3.4)$ \\
Left Hand 1b & $2(7.0)$ \\
Right Thigh 2b & $1(3.4)$ \\
Left Thigh 3 & $1(3.4)$ \\
Right Leg 1b & $1(3.4)$ \\
Left Leg 1a & $1(3.4)$ \\
Left Leg 1b & $1(3.4)$ \\
\hline
\end{tabular}

The most prevalent medical diagnoses were diseases of the respiratory (18.5\%), digestive (14.3\%), circulatory (14.3\%) and urogenital (10.9\%) systems, injuries, poisonings, and other external causes (9.2\%) and endocrine, nutritional and metabolic diseases (5.9\%). In this study, there was no statistically significant relationship between the prevalence of ST and the groups of diseases.

Most patients had altered weight (66.7\%), distributed as follows, according to BMI: underweight (7.7\%), overweight (33.3\%), obesity (22.3\%) and severe obesity (3.4\%). Normal BMI was found in $33.3 \%$ of patients. Most diets were oral (78.4\%), while 32 (21.6\%) were fed by enteral feeding catheter. Forty-two individuals used some type of oxygen therapy 
(28.4\%). Among the subjects, $66.2 \%$ ( $n=98)$ had some degree of dependence, while $31.8 \%$ ( $n=47)$ were totally independent and $33.1 \%(n=49)$ were totally dependent.

The following frequency of medication use was found, according to the five most used pharmacological groups: 87 (58.8\%) antimicrobials, 63 (42.6\%) antiulcerants, $56(37.8 \%)$ anticoagulants, 48 (32.4\%) antihypertensives and 38 (25.7\%) analgesics/antipyretics.

Most individuals (91.2\%) used an intravenous device, $20(14.8 \%)$ with a central catheter and 115 (85.2\%) with a short peripheral catheter. In addition, 134 (90.5\%) had some adhesive tape close to the skin and 25 (16.9\%) had a mechanical limb restraint. Friable skin was identified in 52 (35.1\%) of the patients.

There was a higher frequency (79.3\%) of ST in the upper limbs (23 lesions), followed by five in the lower limbs (17.2\%). Only one injury did not occur in the limbs. As for their classification, 17 (58.6\%) lesions were in level 1a, six in $1 \mathrm{~b}(20.7 \%)$, five in $3(17.3 \%)$ and one in $2 \mathrm{~b}(3.4 \%)$.

According to Table 2, the frequency of ST was statistically higher in older adults, patients fed by an enteral feeding catheter, patients with friable skin and patients with total dependence (zero score) for BADLs.

Table 2 - Distribution of Skin Tears and Prevalence Ratio according to predictor variables in the sample - Metropolitan Region of Porto Alegre, RS, Brazil, 2017.

\begin{tabular}{|c|c|c|c|c|c|}
\hline \multirow{2}{*}{ Variables } & With ST & No ST & \multirow{2}{*}{ PR } & \multirow{2}{*}{$95 \% \mathrm{Cl}$} & \multirow{2}{*}{$\mathrm{p}$} \\
\hline & n(\%) & $\mathrm{n}(\%)$ & & & \\
\hline \multicolumn{6}{|l|}{ Gender } \\
\hline Female & $11(14.5)$ & $65(85.5)$ & 1.00 & & \\
\hline Male & $7(9.7)$ & $65(90.3)$ & 0.672 & $0.27-1.63$ & 0.381 \\
\hline \multicolumn{6}{|l|}{ Age } \\
\hline Up to 59 years & $3(4.7)$ & 61(95.3) & 1.00 & & \\
\hline 60 years or more & 15(17.9) & $69(82.1)$ & 3.81 & $1.15-12.60$ & 0.028 \\
\hline \multicolumn{6}{|l|}{ Skin color } \\
\hline White & $15(12.5)$ & 105(87.5) & 1.00 & & \\
\hline Black/pardo & $3(10.7)$ & 25(89.3) & 0.85 & $0.26-2.76$ & 0.796 \\
\hline \multicolumn{6}{|l|}{ Friable skin } \\
\hline No & $4(4.2)$ & 92(95.8) & 1.00 & & \\
\hline Yes & 14(26.9) & $38(73.1)$ & 6.46 & $2.24-18.62$ & 0.001 \\
\hline \multicolumn{6}{|l|}{ Body Mass Index* } \\
\hline Normal & $6(15.4)$ & $33(84.6)$ & 1.00 & & \\
\hline Altered & $9(11.5)$ & 69(88.5) & 0.75 & 0.28-1.95 & 0.556 \\
\hline \multicolumn{6}{|l|}{ Feeding } \\
\hline Oral & 10(8.6) & 106(91.4) & 1.00 & & \\
\hline Enteral catheter & $8(25.0)$ & $24(75.0)$ & 2.90 & $1.24-6.74$ & 0.013 \\
\hline \multicolumn{6}{|l|}{ Oxygen } \\
\hline Room air & 11(10.4) & 95(89.6) & 1.00 & & \\
\hline Oxygen therapy & $7(16.7)$ & $35(83.3)$ & 1.60 & $0.66-3.86$ & 0.290 \\
\hline \multicolumn{6}{|l|}{ Venous Catheter } \\
\hline No & $2(15.4)$ & 11(84.6) & 1.00 & & \\
\hline Yes & 16(11.9) & $119(88.1)$ & 1.29 & $0.33-5.03$ & 0.706 \\
\hline \multicolumn{6}{|l|}{ Adhesive tape } \\
\hline No & $1(7.1)$ & 13(92.9) & 1.00 & & \\
\hline Yes & $17(12.7)$ & $117(87.3)$ & 0.56 & $0.81-3.91$ & 0.562 \\
\hline \multicolumn{6}{|l|}{ Mechanical restraint } \\
\hline No & $14(11.4)$ & 109(88.6) & 1.00 & & \\
\hline Yes & $4(16.0)$ & $21(84.0)$ & 0.71 & $0.25-1.98$ & 0.515 \\
\hline \multicolumn{6}{|l|}{ Katz Index } \\
\hline Other & $8(8.1)$ & 91(91.9) & 1.00 & & \\
\hline Total dependence & $10(20.4)$ & $39(79.6)$ & 2.52 & $1.06-5.99$ & 0.036 \\
\hline
\end{tabular}

ST: Skin Tear. PR: Prevalence Ratio. Cl: Confidence Interval. ${ }^{*} \mathrm{n}=117$ 
Table 3 shows the pharmacological groups that were considered factors associated with ST. There was a higher occurrence of ST in those using antihypertensives, micronutrients, diuretics, antidepressants and antifungal drugs.

There was no statistically significant difference ( $p$ > 0.05) regarding the frequency of ST and the other pharmacological groups. Table 4 presents the results of the Multivariate Poisson Regression analysis of the predictor variables and the prevalence of ST. The age variable was included in the first and model and excluded in the second model of analysis.

Table 3 - Distribution of Skin Tear and Prevalence Ratio according to medication use - Metropolitan Region of Porto Alegre, RS, Brazil, 2017.

\begin{tabular}{|c|c|c|c|c|c|}
\hline \multirow{2}{*}{ Variables } & With ST & No ST & \multirow{2}{*}{ PR } & \multirow{2}{*}{$95 \% \mathrm{Cl}$} & \multirow{2}{*}{$\mathbf{p}$} \\
\hline & $\mathrm{n}(\%)$ & $\mathrm{n}(\%)$ & & & \\
\hline \multicolumn{6}{|c|}{ Antihypertensives } \\
\hline No & $8(8.0)$ & $92(92.0)$ & 1.00 & & \\
\hline Yes & 10(20.8) & $38(79.2)$ & 2.60 & $1.09-6.17$ & 0.030 \\
\hline \multicolumn{6}{|c|}{ Micronutrients } \\
\hline No & 14(10.4) & 120(89.6) & 1.00 & & \\
\hline Yes & $4(28.6)$ & $10(71.4)$ & 2.73 & $1.04-7.18$ & 0.041 \\
\hline \multicolumn{6}{|l|}{ Diuretics } \\
\hline No & $10(8.7)$ & 105(91.3) & 1.00 & & \\
\hline Yes & $8(24.2)$ & $25(75.8)$ & 2.78 & $1.19-6.49$ & 0.017 \\
\hline \multicolumn{6}{|c|}{ Antidepressants } \\
\hline No & 12(9.2) & 119(90.8) & 1.00 & & \\
\hline Yes & $6(35.3)$ & 11(64.7) & 3.85 & $1.66-8.92$ & 0.002 \\
\hline \multicolumn{6}{|c|}{ Antifungals } \\
\hline No & $16(11.2)$ & $127(88.8)$ & 1.00 & & \\
\hline Yes & $2(40.0)$ & $3(60.0)$ & 3.57 & $1.11-11.50$ & 0.033 \\
\hline \multicolumn{6}{|c|}{ Corticosteroids } \\
\hline No & $14(11.5)$ & 108(88.5) & 1.00 & & \\
\hline Yes & $4(15.4)$ & $22(84.6)$ & 1.34 & $0.48-3.74$ & 0.576 \\
\hline \multicolumn{6}{|c|}{ Antimicrobials } \\
\hline No & $5(8.2)$ & 56(91.8) & 1.00 & & \\
\hline Yes & $13(14.9)$ & $74(85.1)$ & 1.82 & $0.68-4.84$ & 0.229 \\
\hline
\end{tabular}

ST: Skin Tear. PR: Prevalence Ratio. Cl: Confidence Interval.

Table 4 - Multivariate analysis of the predictor variables and the use of medications with the occurrence of Skin Tears - Metropolitan Region of Porto Alegre, RS, Brazil, 2017.

\begin{tabular}{|c|c|c|c|c|c|c|}
\hline Variables & PR & $95 \% \mathrm{Cl}$ & $\mathbf{p}$ & PR & $95 \% \mathrm{Cl}$ & p \\
\hline Age & 2.14 & $0.60-7.68$ & 0.240 & & & \\
\hline Antihypertensives & 2.41 & $0.99-5.87$ & 0.053 & 2.42 & $1.01-5.77$ & 0.046 \\
\hline Diuretics & 2.08 & $0.78-5.53$ & 0.142 & 2.39 & $0.93-6.17$ & 0.070 \\
\hline Antidepressants & 2.55 & $1.06-6.13$ & 0.036 & 2.72 & $1.17-6.33$ & 0.019 \\
\hline Micronutrients & 5.25 & $1.69-16.32$ & 0.004 & 4.93 & $1.64-14.80$ & 0.004 \\
\hline Antifungals & 1.40 & $0.48-4.11$ & 0.535 & 1.37 & $0.49-3.85$ & 0.541 \\
\hline Use of enteral catheter & 1.34 & $0.40-4.42$ & 0.627 & 1.44 & $0.39-5.21$ & 0.579 \\
\hline KATZ Index & 1.59 & $0.50-4.98$ & 0.426 & 1.83 & $0.48-6.93$ & 0.369 \\
\hline
\end{tabular}

PR: Prevalence Ratio. Cl: Confidence Interval. 
In the first model, only antidepressants and micronutrients were associated with ST, increasing the risk of ST by 2.55 and 5.25 times, respectively. In the second model, without the age variable, antihypertensives (PR 2.42), antidepressants (PR 2.72) and micronutrients (PR 4.93) maintained the association with the occurrence of ST.

\section{DISCUSSION}

The prevalence of ST was $12.2 \%$, a value higher than those found in studies conducted in Singapore (6.2\%) $)^{(14)}$; Japan $(3,9 \%)^{(2)}$, Australia (8\% and 11\%) $)^{(6,15-16)}$ and Brazil $(3,3 \%)^{(17)}$ and lower than those found in a study in Canada $(22 \%)^{(8)}$. These differences may be related to the methodological diversity of the sampling in the different studies, especially regarding age and study setting. While some studies investigated only older adults ${ }^{(2,8)}$, others also included neonatal/ pediatric patients ${ }^{(15)}$ and adults ${ }^{(14,17)}$. Also, the studies were conducted in settings such as long-term care institutions ${ }^{(2,8)}$, oncological care centers ${ }^{(17)}$ or intensive care units ${ }^{(14)}$. In the present study, both adult and older adults hospitalized in clinical/surgical or intensive care units were considered.

There were no ST in the $15 \mathrm{ICU}$ patients, which may be related to the sample size or also to the greater level of care provided to these patients, as they are in a more serious health situation. In the ICUs, there is a better quantitative division of the nursing work, so patients receive more constant care and are more likely to not develop ST. In inpatient units, nursing professionals have more patients under their care, which is a risk factor, as the level of nursing care directly affects the occurrence of skin lesions ${ }^{(18)}$.

Older adults had a higher frequency of ST (17.9\% versus $4.7 \%)$, which is related to the aging process itself. Likewise, the prevalence of ST was also higher in those with friable skin (26.9\% versus $4.3 \%)$. Other studies also identify advanced age as a risk factor for $\mathrm{ST}^{(6,15)}$, whereas a Brazilian study with hospitalized cancer patients found no relationship between these variables ${ }^{(17)}$.

The skin of older adults is more predisposed to ST due to the various physiological changes that occur during the aging process, such as reduced nociception and tactile sensitivity, decreased collagen production, reduced vascularization, reduced inflammatory response and decreased thickness of the dermis and subcutaneous tissue ${ }^{(2,19-20)}$. The good organization of the biological, structural and functional components of the skin allows the organism to keep it protected. In older adults, the decrease in the lipid layer thickness makes the protection mechanism less efficient. In addition to the fat layer, the production of sebaceous and sweat glands result in the hydrolipidic mantle, which makes the skin more resistant. This protection is easily affected with procedures that occur in hospitals, as the use of products such as solvents or repeated washing with insufficient rinsing, which changes the $\mathrm{pH}$ and reduces the skin layer ${ }^{(21)}$.

The use of an enteral feeding catheter was related to a higher prevalence of ST ( $25 \%$ versus $8.6 \%$ ), which differs from a study with Japanese older adults ${ }^{(18)}$. There was no relationship between injuries and BMI, which is also demonstrated in international studies ${ }^{(17-18)}$.
There was a statistically significant difference regarding the prevalence of ST in patients using micronutrients, both in the bivariate and multivariate analysis (odds 4.93 times greater). Evidence of an association between malnutrition and Pressure Injuries is identified in the scientific literature, but such a clear relationship does not occur for ST. However, recommendations from international consensus point to the need to optimize nutrition and systemic hydration for the prevention of $\mathrm{ST}^{(1,6)}$.

The mean frequency/distribution of injuries was $1.6 \pm 0.7 \mathrm{ST}$ per subject with an injury, $10(55.5 \%)$ patients had one injury and the maximum number was three ST. A predominance of one injury is also evidenced in other studies, such as one conducted with 2197 adults hospitalized in Australia ${ }^{(6)}$ (61.5\% with a ST). Among the older adults living in a long-term institution in Japan, none had multiple $\mathrm{ST}^{(18)}$. It should be noted that most studies do not assess the number of ST per person, which makes it difficult to discuss this data. The predominance of one injury may indicate that skin care increases after the onset of the first skin tear, which decreases the occurrence of others.

The predominance of ST in the upper (23) and lower limbs (5) is associated, in the literature, with limb movement, use of intravascular devices or the need for assistance with mobility, transfer or locomotion ${ }^{(22)}$, which are common situations in inpatient units. The occurrence of ST in the upper limbs is predominant in the international literature: $43 \%$ of patients in acute care in Singapore ${ }^{(14)} ; 49.4 \%$ of Australian patients ${ }^{(6)} ; 50 \%$ of older adults in long-term care facilities in Japan $^{(2)}$ and $60.4 \%$ of hospitalized Australian older adults ${ }^{(23)}$.

The higher prevalence of ST in totally dependent patients has been explained by the patient's clinical and cognitive status, which results in the need for help in transfer, mobility, bed positioning and assistance with basic activities, as already shown in international literature ${ }^{(1,3,17,22)}$. In the present study, a relationship between degree of dependence and ST was found only in the bivariate analysis and was not confirmed in the regression model.

There was a higher frequency of the level 1a (17 lesions), while five lesions were in level 3. These data differ from studies carried out in Australia ${ }^{(6)}$, Singapore ${ }^{(14)}$ and Brazil ${ }^{(17)}$, in which level 3 lesions predominated (38.8\%; $43 \%$, and $55.5 \%$, respectively). Older adults living in long-term facilities in $\mathrm{Japan}^{(18)}$ had a higher prevalence of the level $1 \mathrm{~b}(57.1 \%)$.

The use of adhesives and medical devices has not been associated with the occurrence of $\mathrm{ST}^{(17)}$, although some authors associate ST with the removal of adhesive tapes and bandages ${ }^{(4,9)}$. These differences in results may be related to the type and quality of the adhesives available in each setting and to the products used for their removal.

The bivariate analysis showed a relationship between the use of antihypertensives, micronutrients, diuretics, antifungals and antidepressants and a higher prevalence of ST. There was no association with the use of corticosteroids and anticoagulants. In the international literature, the relationship between drugs and ST is not well defined: while some studies have pointed out polypharmacy and chronic use of corticosteroids ${ }^{(1,18)}$ as factors associated with ST, other studies did not find any relationship $^{(2,21)}$. Therefore, further evidence is necessary. 
In the multivariate model, antihypertensives, antidepressants and micronutrients maintained a significant relationship with the occurrence of ST, with increases of 2.42, 2.72 and 4.93 , respectively. The model that included the variable age showed no relationship between this variable and the occurrence of ST, indicating that ST can occur at any age and are not exclusive to older adults. The relationship with the use of antidepressants diverged from the findings of studies on ST, which usually associate ST with chronic use of corticosteroids (due to the potential side effect of inhibition of collagen synthesis) ${ }^{(1,18)}$, anticoagulants (due to the greater predisposition to ecchymosis and senile purpura) $)^{(24)}$ or polypharmacy ${ }^{(25)}$. Studies with a larger sample size and specific studies on drugs and ST should be carried out to clarify their relationship.

It should also be noted that this study has limitations such as the evaluation of only one hospital and collection of some variables in medical records, which can decrease the accuracy of the measure, especially regarding nutritional analysis (weight, height and BMI), which needs an objective and accurate assessment.

\section{CONCLUSION}

The study identified a prevalence of $12.2 \%$ of ST among hospitalized adults and older adults. This can be considered a high value compared to other investigations on the subject. It shows, therefore, that ST are present in the nurses' work setting and that measures for its prevention, identification and treatment must be adopted, even though its recognition as an adverse event is recent and little studied in Brazil.

In this sense, it is essential to provide daily care to individuals with fragile skin, identifying patients at risk for ST, even if there is no specific instrument for this. The creation and implementation of care protocols for the prevention and treatment of ST can help preventing and minimizing damage to patients at risk. It is also necessary to give greater emphasis to ST in the training of nurses, both in undergraduate training and in continuing education in health institutions, aiming to train the new and current generation of nurses who will care for the older adult population.

Despite its limitations, this study advances the understanding of the state of the art on ST in the context of public health care in Brazil, which still has little epidemiological data. The need to expand research on ST in the Brazilian context is emphasized, especially with longitudinal studies with a focus on polypharmacy, given that ST are especially common among older adults, the fastest growing population in the world. There is also a need for studies to develop instruments for risk assessment and interventions for the prevention and management of ST.

\section{RESUMO}

Objetivo: Identificar a prevalência, os fatores relacionados e classificar as Lesões por Fricção em adultos e idosos hospitalizados. Método: Estudo de prevalência com adultos e idosos em unidades de internação e de tratamento intensivo de um hospital do Sul do Brasil. Utilizou-se a STAR Skin Tear Classification System para análise das lesões. Os dados foram coletados por exame físico e consulta em prontuário. Calculou-se a Razão de Prevalência por Regressão de Poisson com variância robusta. Resultados: Participaram 148 pacientes. Foram encontradas 29 Lesões por Fricção (média 1,6士0,7) em 18 indivíduos (prevalência de 12,2\%). As variáveis idade, pele friável, alimentação por cateter enteral, grau de dependência, uso de anti-hipertensivo, micronutriente, diurético, antidepressivo e de antifúngico foram associadas às lesões na análise bivariada. No modelo final multivariado, anti-hipertensivo RP 2,42 (IC 95\% 1,015,77), antidepressivo RP 2,72 (IC 95\% 1,1-6,33) e micronutriente RP 4,93 (IC 95\% 1,64-14,80) mantiveram relação. Conclusão: A prevalência de lesões foi de $12,2 \%$, evidenciando sua presença no cenário de atenção em saúde, sobretudo nos cuidados de enfermagem. Protocolos assistenciais precisam ser elaborados para sua prevenção, identificação e tratamento precoce.

\section{DESCRITORES}

Ferimentos e Lesões; Fricção; Pele; Pacientes Internados; Cuidados de Enfermagem.

\section{RESUMEN}

Objetivo: Identificar la prevalencia y los factores relacionados de las Lesiones por Fricción en adultos y adultos mayores hospitalizados. Método: Se trata de un estudio de prevalencia realizado entre adultos y adultos mayores en las unidades de internación y de tratamiento intensivo de un hospital del Sur de Brasil. Se utilizó el STAR, Skin Tear Classification System, para analizar las lesiones. Los datos se recogieron mediante examen físico y consulta de prontuario. Se calculó la Razón de Prevalencia por Regresión de Poisson con varianza robusta. Resultados: Participaron 148 pacientes. Se encontraron 29 Lesiones por Fricción (media 1,6 $\pm 0,7$ ) en 18 individuos (prevalencia del 12,2\%). Las variables edad, piel friable, alimentación por catéter enteral, grado de dependencia, uso de antihipertensivo, micronutriente, diurético, antidepresivo y antimicótico estaban asociadas a las lesiones en el análisis bivariado. En el modelo final multivariado, antihipertensivo RP 2,42 (IC 95\% 1,01-5,77), antidepresivo RP 2,72 (IC 95\% 1,1-6,33) y micronutriente RP 4,93 (IC 95\% 1,64-14,80) se mantuvieron relacionados. Conclusión: La prevalencia de las lesiones era del 12,2\%, lo que demuestra su presencia en el escenario de la atención en salud, sobre todo en los cuidados de enfermería. Es necesario elaborar protocolos asistenciales para su prevención, identificación y tratamiento precoz.

\section{DESCRIPTORES}

Heridas y Lesiones; Fricción; Piel; Pacientes Internos; Atención de Enfermería.

\section{REFERENCES}

1. LeBlanc K, Baranoski S; Skin Tear Consensus Panel Members. Skin tears: state of the science: consensus statements for the prevention, prediction, assessment, and treatment of skin tears. Adv Skin Wound Care. 2011;24(9 Suppl):2-15. doi: https://doi.org/10.1097/01. ASW.0000405316.99011.95

2. Koyano Y, Nakagami G, lizaka S, Minematsu T, Noguchi H, Tamai N, et al. Exploring the prevalence of skin tears and skin properties related to skin tears in elderly patients at a long-term medical facility in Japan. Int Wound J. 2014;13(2):189-97. doi: https://doi.org/10.1111/ iwj. 12251 
3. Strazzieri-Pulido KC, Peres GRP, Campanili TCGF, Santos VLCG. Skin tears prevalence and associated factors: a systematic review. Rev Esc Enferm USP. 2015;49(4):674-80. doi: https://doi.org/10.1590/S0080-623420150000400019

4. Santos El. Skin tears treatment and prevention by nurses: an integrative literature review. Rev Gaucha Enferm. 2014;35(2):142-9. doi: http://dx.doi.org/10.1590/1983-1447.2014.02.45178

5. LeBlanc K, Baranoski S, Christensen D, Langemo D, Edwards K, Holloway S, et al. The art of dressing selection: a consensus statement on skin tears and best practice. Adv Skin Wound Care. 2016;29(1):32-46. doi: https://doi.org/10.1097/01.ASW.0000475308.06130.df

6. Munro EL, Hickling DF, Williams DM, Bell JJ. Malnutrition is independently associated with skin tears in hospital inpatient setting-findings of a 6-year point prevalence audit. Int Wound J. 2018;15(4):527-33. doi: https://doi.org/10.1111/iwj.12893

7. Lopez V, Dunk AM, Cubit K, Parke J, Larkin D, Trudinger M, et al. Skin tear prevention and management among patients in the acute aged care and rehabilitation units in the Australian Capital Territory: a best practice implementation project. Int J Evid Based Healthc. 2011;9(4):429-34. doi: https://doi.org/10.1111/j.1744-1609.2011.00234.x

8. Leblanc K, Christensen D, Cook J, Culhane B, Gutierrez O. Prevalence of skin tears in a long-term care facility. J Wound Ostomy Continence Nurs. 2013;40(6):580-4. doi: https://doi.org/10.1097/WON.0b013e3182a9c111

9. Peres GRP, Strazzieri-Pulido KC, Santos VLCG. Prevenção de lesões por friccão. In: Domansky RC, Borges EL. Manual para prevenção de pele: recomendações baseadas em evidências. Rio de Janeiro: Rubio; 2014. p. 141-64.

10. Straizzieri-Pulido KC, Santos VLCG, Carville K. Cultural adaptation, content validity and inter-rater reliability of the "STAR Skin Tear Classification System". Rev Latino Am Enfermagem. 2015;23(1):155-61. doi: http://dx.doi.org/10.1590/0104-1169.3523.2537

11. Duarte YAO, Andrade CL, Lebrão ML. O índice de Katz na avaliação da funcionalidade dos idosos. Rev Esc Enferm USP. 2007;41(2):31725. doi: http://dx.doi.org/10.1590/S0080-62342007000200021

12. Organização Mundial de Saúde. Classificação internacional de doenças e problemas relacionados à saúde (CID-10). 10 ed. São Paulo: EDUSP; 2017.

13. World Health Organization. Obesity preventing and managing the global epidemic. Report of a WHO consultation on obesity [Internet]. Geneva: WHO; 2000 [cited 2019 Oct 25]. Available from: http://www.who.int/nutrition/publications/obesity/WHO_TRS_894/en/

14. Chang YY, Carville K, Tay AC. The prevalence of skin tears in the acute care setting in Singapore. Int Wound J. 2016;13(5):977-83. doi: https://doi.org/10.1111/iwj.12572

15. Santamaria N, Carville K, Prentice J. Woundswest: identifying the prevalence of wounds within western Australia's public health system. EWMA J. 2009 [cited 2019;9(3):13-8.

16. McErlean B, Sandison S, Muir D, Hutchinson B, Humphreys W. Skin tear prevalence and management at one hospital. Prim Intent. 2004;12(2):83-8.

17. Amaral AFS, Strazzieri-Pulido KCS, Santos VLCG. Prevalence of skin tears among hospitalized patients with cancer. Rev Esc Enferm USP. 2012;46(spe n.):44-50. doi: http://dx.doi.org/10.1590/S0080-62342012000700007

18. Sanada H, Nakagami G, Koyano Y, Izaka S, Sugama J. Incidence of skin tears in the extremities among elderly patients at a long-term medical facility in Japan: a prospective cohort study. Geriatr Gerontol Int. 2015;15(8):1058-63. doi: https://doi.org/10.1111/ggi.12405

19. Tristão FS, Feijó CK, Herzer DM, Hammes HR. Prevenção e tratamento de lesões cutâneas em idosos. In: Tristão FS, Padilha MAS. Prevenção e tratamento de lesões cutâneas: perspectivas para o cuidado. Porto Alegre: Moriá; 2018. p. 119-51.

20. LeBlanc K, Baranoski S. Skin Tears: the forgotten wound. Nurs Manag. 2014;45(12):36-46. doi: 10.1097/01.NUMA.0000456648.49038.df

21. Oliveira ARA. A pele em diferentes etapas da vida. In: Domansky RC, Borges EL. Manual para prevenção de lesões de pele: recomendações baseadas em evidências. $2^{a}$ ed. Rio de Janeiro: Rúbio; 2014. p. 9-40.

22. Hawk J, Shannon M. Prevalence of skin tears in elderly patients: a retrospective chart review of incident reports in 6 long-term care facilities. Ostomy Wound Manage. 2018;64(4):30-6.

23. Lewin GF, Newall N, Alan JJ, Carville KJ, Santamaria NM, Roberts PA. Identification of risk factors associated with the development of skin tears in hospitalized older persons: a case-control study. Int Wound J. 2016;13(6):1246-51. doi: https://doi.org/10.1111/iwj.12490

24. Serra R, lelapi N, Barbetta A, Franciscis. Skin tears and risk factors assessment: a systematic review on evidence-based medicine. Int Wound J. 2017;15(1):38-42. doi: https://doi.org/10.1111/iwj.12815

25. Torres FS, Blanes L, Galvão TF, Ferreira LM. Development of a manual for the prevention and treatment of skin tears. Wounds. 2019;31(1):26-32 